\title{
HOMELESSNESS IN ALBERTA: The Demand for Spaces in Alberta's Homeless Shelters*
}

\author{
Ronald Kneebone, J.C. Herbert Emery and Oksana Grynishak \\ The School of Public Policy, University of Calgary
}

\section{SUMMARY}

Homelessness in Alberta is overwhelmingly concentrated in Calgary and Edmonton, with almost two-thirds of total provincial shelter usage in the former. Calgary also experiences much greater fluctuations in shelter use. Three interconnected economic factors - the supply of rental accommodations, the state of the labour market and the inward flow of jobseekers - go a long way toward explaining both Calgary's unusually large share of Alberta's homeless as well as the swings in shelter use. Calgary has proportionately less than half as many rental units as Edmonton and this gap is widening. Simultaneously, Calgary, more than any other Canadian city, attracts a significant share of migrants during times of economic growth increasing demand for affordable housing and then shelter space when the availability of housing approaches zero. The recent fall in shelter use in Calgary (and so Alberta) may therefore prove temporary should a recovering economy attract more arrivals and so drive up shelter use again. The provincial government's recent efforts to increase the stock of affordable housing are appropriate but greater progress could be made if it devised ways to enlist the energy and efficiency of the private sector to expand Calgary's rental market.

\footnotetext{
* This paper is a condensed version of a report prepared for the Alberta Ministry of Housing and Urban Affairs. The opinions expressed in this paper are those of the authors and have not been endorsed or approved by the Government of Alberta. We thank Eva Plociennik, Barry Bezuko and an anonymous reviewer for helpful comments and we thank Kate White, Mic Farrell, Diane Richards and Lindsay Kendall for help with data. We remain solely responsible for any errors.
} 


\section{INTRODUCTION}

Across Canada, the number of emergency shelter beds grew from 11,852 in 2006 to 16,758 in 2009, an increase of over 40 percent. In Canada in 2009 there was an average of 50 shelter beds provided per 100,000 people. This ranged from a low of nine beds (per 100,000) in Prince Edward Island, 35 in Quebec, 47 in British Columbia and 53 in Ontario to a high of 88 beds per 100,000 in Alberta. ${ }^{l}$ These statistics suggest that Canadian provincial governments in general, and the government of Alberta in particular, have responded strongly to the need for shelter spaces.

Providing shelter spaces, however, is not a solution to homelessness. To its credit, the government of Alberta has, in conjunction with community-based organizations and partners, introduced a number of policy initiatives and research efforts intended to get at the root causes of homelessness. These include the Ministry of Housing and Urban Affairs' implementation of a 10-year plan to end homelessness, the adoption of the Housing First approach for addressing homelessness, a commitment to fund the provision of 8,000 affordable housing units by 2019 and the establishment of the Alberta Homelessness Research Consortium in 2010. The purpose of this report is to provide a summary of the findings of one piece of research in that agenda, the goal of which is to end homelessness in Alberta.

In this summary report we describe recent trends in shelter stays in Alberta and examine the reasons behind fluctuations in those trends. We focus on shelter use in Alberta's two largest cities and find that patterns of shelter use differ between Edmonton and Calgary. In particular, we find that shelter use is much larger and more volatile in Calgary than in Edmonton and that in recent years, most of the fluctuations in shelter use in Alberta have been due to fluctuations in Calgary. We investigate a variety of possible explanations for these differences, but find that differences in in-migration, labour markets and, most particularly, in housing stock best explain them. We conclude that public policies with respect to homelessness would benefit from research into why housing markets sometimes fail to maintain an adequate stock of affordable housing and research into what public policies might be enacted to better engage the private sector in maintaining such a stock.

\section{OUR APPROACH}

An understanding of the factors that cause people to move in to and out of homeless shelters can be developed from one of three broad perspectives. One is a long-run perspective that emphasizes the evolution of society's treatment of the mentally challenged, the spread of drug use, the gradual change in the distribution of income and even the introduction of shelters themselves amongst the potential sources of demand for shelter spaces. ${ }^{2}$ Understanding and evaluating these long-term determinants of shelter demand is challenging because they describe

\footnotetext{
1 These data are from "2009 Shelter Capacity Report, Homeless Individuals and Families Information System," Human Resources and Skills Development Canada, Ottawa, 2010. http://www4.hrsdc.gc.ca/.3ndic.1t.4r@ eng.jsp?preview $=1 \&$ iid $=44$

2 An interesting and accessible discussion of the long-term determinants of homelessness is Brendan O'Flaherty, Making Room: The Economics of Homelessness (Cambridge, MA: Harvard University Press), 1996.
} 
slowly changing trends and adjustments occurring over decades. A second perspective emphasizes the very short-run determinants of shelter use - the demand for shelter space from one day to the next. Here the emphasis would be on the relative attractiveness of living in a shelter as opposed to living on the street. Important drivers would include weather conditions and the demands placed on the homeless by shelter providers. ${ }^{3}$ A third perspective emphasizes an intermediate time frame, one that takes as a given the slowly changing societal trends of the first perspective and ignores the day-to-day influences of weather conditions. This intermediate time frame is what we examine here.

We examine the issue of shelter demand from an economic perspective. Thus our emphasis will be on understanding the relationship between shelter use and factors such as the state of the labour and housing markets, levels of social assistance and the size of the population at risk of homelessness. The role of non-economic determinants of shelter use, particularly the personal disabilities and challenges of the homeless population, is beyond the scope of this study.

The Alberta Ministry of Housing and Urban Affairs (HUA) provided us with data describing average monthly shelter use in 10 cities in Alberta covering the period from July 2007 to August 2010. Our focus in this summary report is on shelter use in Calgary and Edmonton. As we report below, the overwhelming majority of homeless shelter spaces are found in those two cities.

\section{SOME BASIC FACTS}

Two basic facts about shelter use in Alberta are revealing. First, a snapshot of shelter use in 2009 reveals that Calgary and Edmonton accounted for 90 percent of all shelter use in the province. However, despite the two cities being similar in total population, 63 percent of all shelter use in the province was in Calgary while only 28 percent was in Edmonton. Second, the Calgary Drop-In Centre, which controls two shelters (Riverfront and Hillhurst Centre) in Calgary, controlled an average of 34 percent of all shelter spaces in the province in 2009 and was easily the largest provider of shelter spaces in the province. The next largest shelter provider - Hope Mission in Edmonton - accounted for just under 15 percent of the province's shelter spaces in 2009.

While the problem of homelessness impacts virtually all communities in Alberta and while it is the target of the government's policy actions wherever it occurs, these facts indicate that the problem of homelessness is disproportionately a "big city" problem. ${ }^{4}$ This is not surprising as homelessness is typically judged to be a problem that plagues large urban centres more so than smaller urban centres or rural areas. What is surprising, however, is the dramatic difference in the prevalence of shelter use in two large urban centres that are quite similar in terms of population and that would appear at first blush to be quite similar in other respects as well.

3 For example, shelters differ by their tolerance for alcohol and substance use, their opening and closing times, their location, etc.

4 We say homelessness is disproportionately a big city problem because while together Calgary and Edmonton account for 69 percent of Alberta's population, 90 percent of the province's homeless shelter users reside in those two cities. This is not to say that homelessness is an insignificant problem in smaller centers. On the contrary, as a proportion of their local population, homelessness can be as serious a problem in smaller centers and it is for that reason that the government provides considerable resources to dealing with homelessness wherever it is experienced. 
Over the period July 2007 to May 2009 overnight stays in Calgary increased by an average of 31 per month, but have been stable since that time. In Edmonton the number of overnight stays was stable with no significant trend before mid-2009, but it declined slightly by four fewer overnight stays per month afterward. The key observation is that since the middle of 2009, something has happened to halt a rapid growth in shelter stays in Calgary and that this event has had a more modest impact on stays in Edmonton. We calculate that the adjustment from the earlier trend to a more or less stable number of overnight stays means that in Calgary there were, by August 2010, approximately 350 fewer shelter stays each month than would have been the case had the earlier trend continued beyond mid-2009.

It is not surprising to know that weather plays a role in determining shelter use. To remove this influence Figure 1 shows, for Alberta, Calgary and Edmonton, the number of overnight stays in HUA-funded shelters from the same month a year earlier. ${ }^{5}$ The line shows, for example, that in July 2008 there were 451 more shelter stays in the province than was the case in July 2007. Comparing the same two months, the green bar indicates that in Calgary there were an additional 318 shelter stays and the red bar indicates that in Edmonton there were an additional 21 shelter stays compared to the same month a year previous. The pattern of change shown by the line tells a "good news" story of declining shelter use in the province since June 2009. The patterns of change shown by the green and red bars show that changes in the provincial total are almost wholly due to changes in Calgary.

FIGURE 1: Year over Year Changes in Overnight Stays

Calgary, Edmonton, and Alberta

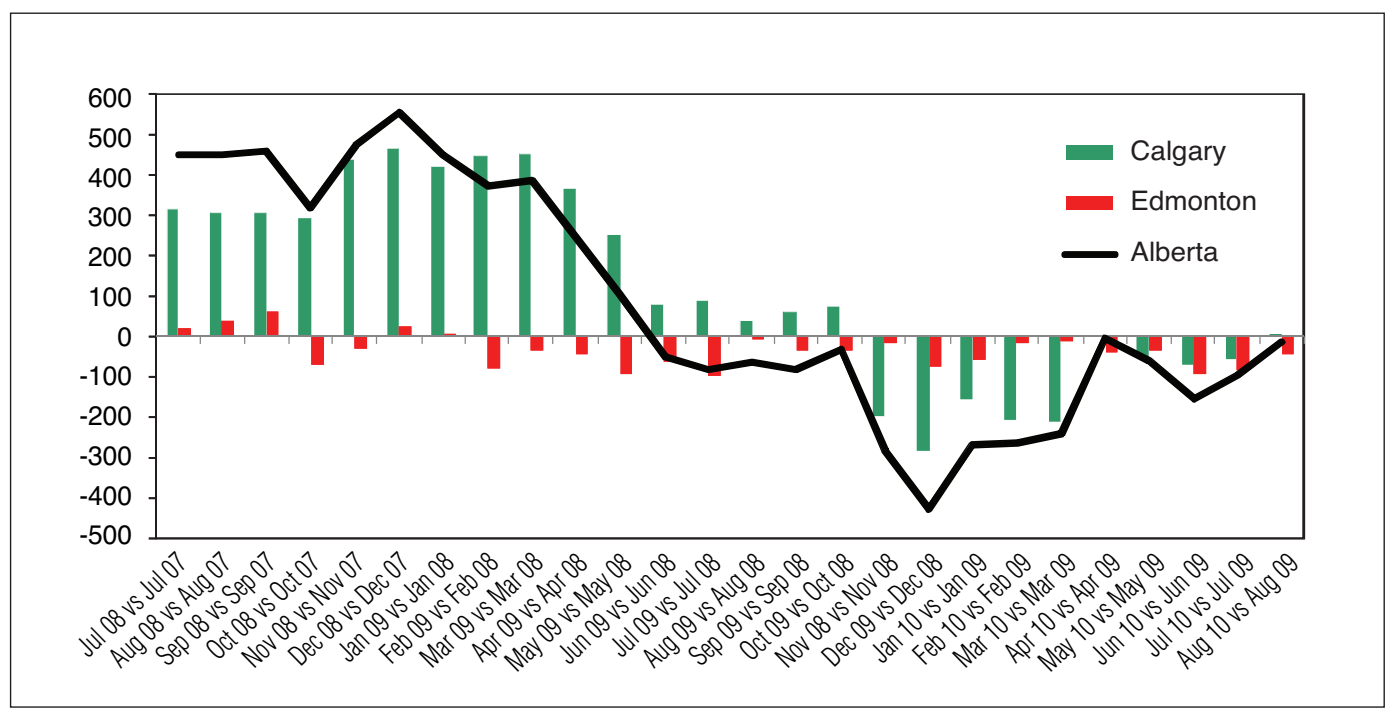

The information contained in Figure 1 is interesting since by most accounts the cities of Calgary and Edmonton are quite similar. To have such a different experience with respect to the size of the homeless and with respect to how the problem has evolved over time suggests that comparing the characteristics of the two cities will provide useful insights into the determinants of shelter use.

5 On the assumption that weather conditions in any month are very similar from year to year, month-to-month comparisons have the effect of removing the influence of weather conditions on shelter stays. 


\section{EXPLAINING THE FACTS}

Why have two large, seemingly similar cities had such different experiences with respect to shelter use? An economic perspective on shelter use emphasizes considerations such as the state of the local labour market, the generosity of publicly provided income supports and the state of the housing market as reflected in vacancy rates, rents, and the supply of housing units at prices affordable to those most at risk of homelessness. Housing market variables are affected by the size of the vulnerable population, a variable influenced by in-migration to the local housing market and the number of people living on social assistance. Although we investigated the role of all of these factors, we found that only three play a predominant and interconnected role in determining shelter use: the supply of rental accommodation, the state of the labour market and the rate of in-migration. ${ }^{6}$

Data on the supply of rental accommodation shows a remarkable difference between Calgary and Edmonton. The stock of housing units available for rent in Calgary (38 units per 1,000 population) is currently less than half what it is in Edmonton (86 units per 1,000 population). ${ }^{7}$ What's more, while over the past 20 years the stock of rental accommodations has fallen in both cities, it has fallen by much more in Calgary. Thus Edmonton not only has a much larger stock of rental accommodation, it has also proven better at maintaining the size of that stock in the face of population growth. ${ }^{8}$ This is true even in the face of a similar number of condominium conversions in the two cities. ${ }^{9}$ The difference in the stock of rental accommodation is a potentially important explanation for the difference in the number of homeless shelter users in the two cities, but cannot explain the key observation noted earlier that since the middle of 2009, something has happened to halt a rapid growth in shelter stays in Calgary while having a more modest impact on shelter stays in Edmonton. This requires another explanation.

6 We took into account a number of other factors. Rents and vacancy rates on comparable rental units in the two cities do not change over time in a way that would help explain differences in shelter use. The level of income available to those on social assistance, both the absolute amount and the amount relative to the cost of rental accommodations, is often identified as a measure of the lack of housing affordability. We found little evidence to suggest that shelter use is related to these measures. Finally, the pattern of change in the number of recipients of social assistance does not suggest a causal effect on shelter use. It is important to emphasize that the limitations of the data prevent precise estimates of the influences these variables may have on shelter use. Our data on shelter use covers only three years (2007-2010) and a longer time series would be useful for identifying more precisely the role of these variables. Another difficulty is that data on many of the hypothesized determinants of shelter use are available only annually thus making correlations with the monthly data on shelter use challenging. Precise estimates of these influences are therefore impossible and instead it is often the case that only broader inferences can be made. Despite these problems, we nonetheless believe our conclusion that differences in shelter use in Calgary and Edmonton is best explained by differences in in-migration, the state of the labour market and the stock of affordable housing is warranted.

7 The supply of rental accommodations housing is defined as the total stock of single-detached, semi-detached, row, apartment and other forms of housing intended for rental. Source: CMHC, Canadian Housing Statistics, various years. Population data are from City of Calgary and City of Edmonton Civic Census for 2010.

8 During the period of strong economic growth from 2000 to 2008, an average of 10 percent of all new dwellings constructed in Edmonton was intended for rental accommodation. This compares to an average of less than two percent in Calgary over the same period.

9 As well as not adding significant numbers via new construction, Canada Housing and Mortgage Corporation reports that from 2001 to 2009, Calgary lost approximately 7,500 apartment units to condominium conversions. It is interesting that over the same period Edmonton lost approximately 9,600 units to condominium conversions and yet was still better able to maintain its stock of affordable housing than Calgary. The higher number of rental-tocondominium conversions in Edmonton highlights the importance of the construction of rental housing that occurred in Edmonton after 2000. Over that same period, Calgary's lack of rental housing construction meant that the condominium conversions contributed to a 19 percent loss in the absolute number of rental housing units between 2001 and 2009. Data on condominium conversions is from CMHC, Rental Market Report, Calgary CMA, Fall 2010, and CMHC Edmonton Multi-Family Market Trends, January. Presentation by Richard Goatcher, Senior Market Analyst, January 2010, http://www.eaa.ab.ca/upload/documents/CMHC\%20Presentation\%20Jan\%20GM\%202010.pdf 
An important source of population increase in Alberta has traditionally been in-migration. Between them, Calgary and Edmonton have absorbed 72 percent of all in-migrants to the province since 1987. Over that period, however, Calgary averaged over twice as many inmigrants (12,243 per year) as Edmonton (5,904 per year). What implication might this difference have on shelter use in the two cities?

To understand the implication of this difference, we investigated the potential influence of labour market conditions on in-migration to each city. Specifically, we examined the relationship between net in-migration to each city and the level of employment in that city relative to the rest of the country. The ratio of city employment to national employment is relevant since an important consideration for potential migrants is their employment prospects in the city they are considering relative to their employment prospects elsewhere. Using data for the period 1987-2009, we found that Calgary and Edmonton are unique amongst large Canadian cities in exhibiting a close relationship between net interprovincial in-migration (people moving between provinces) and employment conditions relative to the rest of the country. The relationship is particularly strong in Calgary with respect to international migrants (people moving to Canada from other countries); strong employment growth in Calgary relative to the rest of the country is a magnet for international migrants. The same relationship for Edmonton is much weaker.

What do these three considerations - a much smaller stock of rental accommodations in Calgary as opposed to Edmonton, significantly more in-migration to Calgary than Edmonton, and a closer relationship between in-migration and the state of the labour market in Calgary than in Edmonton - mean when considered together? All else being equal, one might expect that improved employment opportunities would reduce the risk of homelessness and perhaps better enable people to leave shelters. However, such an expectation rests on an assumption that the change in employment has no influence on other determinants of shelter use. The relationships discussed above show that increases in employment in Calgary relative to elsewhere are closely related with increases in net in-migration. This consideration, plus the fact Calgary has a small stock of rental units suggests that when the Calgary labour market expands relative to markets elsewhere, net in-migration rises and increases the demand for rental accommodations in the city. With a small and falling supply of rental accommodations and the local housing market's failure to expand supply, this results in upward pressure on shelter use.

Figure 2 provides evidence supporting this line of causation for Calgary. It does so by relating, for Calgary, the number of overnight stays relative to the same month a year earlier to the ratio of employment in the city compared to elsewhere relative to the same month a year earlier. ${ }^{10}$ The movements of these two variables strongly support our suggested line of causation, one that suggests that a strong local labour market in Calgary puts upward pressure on shelter use in that city.

${ }^{10}$ Labour force data for regional labour markets and nationally are available from CANSIM Table 2820054. 
FIGURE 2: Year over Year Changes in Shelter Stays and the Employment Ratio, Calgary

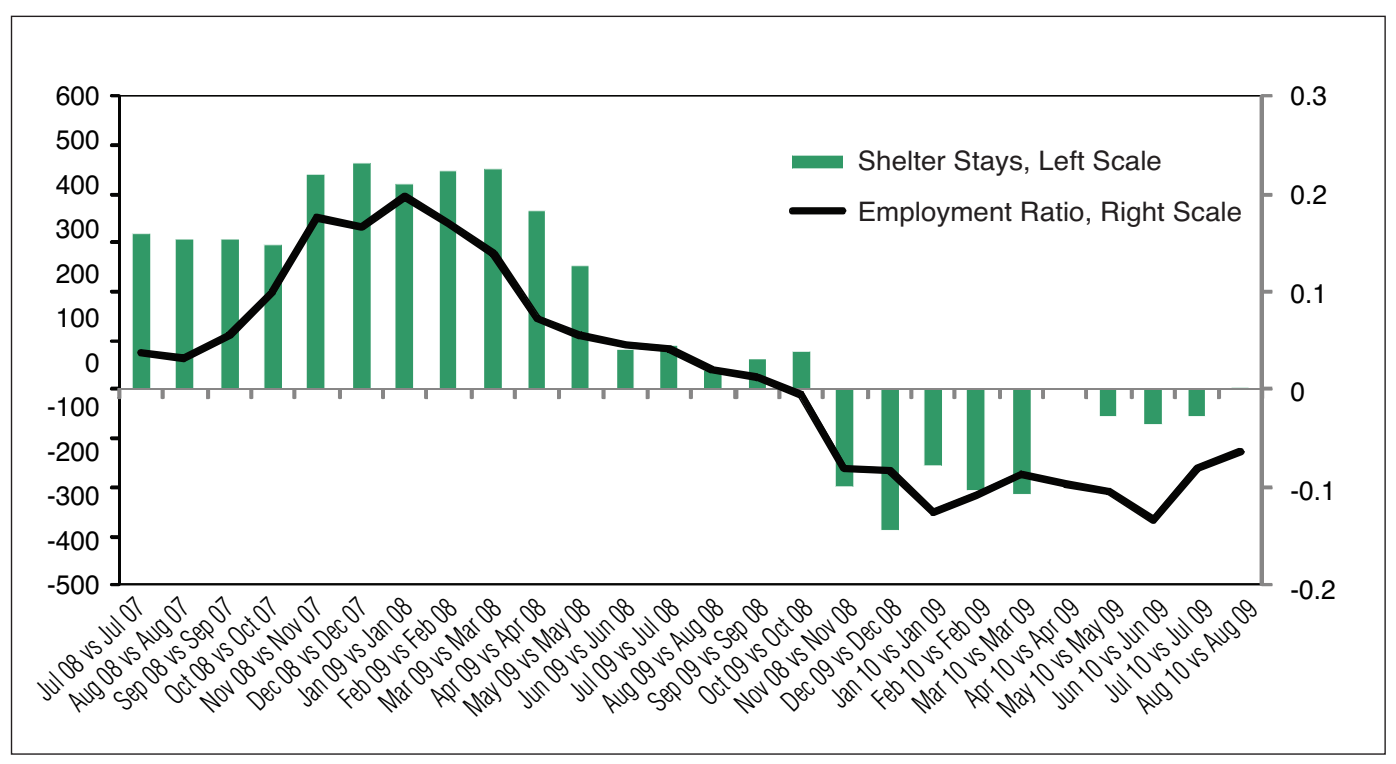

In Edmonton this line of causation is broken in two places. First, in Edmonton a relatively strong local labour market does not attract as many in-migrants as Calgary. Second, since the local housing market has been effective at maintaining the supply of rental accommodations, in-migrants are more likely to be absorbed into the local housing market without putting upward pressure on shelter stays. As a result of these two broken links in our story of causation, it is difficult to suggest that the shallow decline in shelter use in that city is related to any labour market or migration variables. An examination of the relationship shown in Figure 2 using information for Edmonton confirms the lack of a consistent relationship between shelter stays and relative levels of employment in that city.

\section{DISCUSSION AND CONCLUSION}

Our goal in this study was to gain an understanding of the key determinants of homeless shelter use in Alberta. In this summary report, we have concentrated on shelter use in Edmonton and Calgary because 90 percent of shelter users in Alberta live in those cities. We have examined the issue of shelter demand from an economic perspective and so our emphasis has been on understanding the relationship between shelter use and factors such as the state of the labour and housing markets and levels of social assistance, among others. The role of noneconomic determinants of shelter use, particularly the personal disabilities and challenges of the homeless population, is beyond the scope of this study.

As Figure 1 illustrates, the basic facts show that the pattern of change in homeless shelter use in Alberta since 2007 is almost wholly explained by the pattern of change in homeless shelter use in Calgary. While many factors play a role in determining shelter use, in Calgary the predominant explanation has to do with a labour market that attracts and sheds migrants as it strengthens and weakens combined with a small and shrinking stock of rental units. Thus a strong labour market in Calgary relative to elsewhere increases shelter use in that city.

Referring to the patterns of change in shelter use shown in Figure 1, our explanation for the fall 
in shelter use in Alberta since mid-2009 is a weakening of the labour market in Calgary relative to elsewhere that began at approximately the same time. Our warning is that a recovery in the Calgary labour market relative to elsewhere may, in the absence of effective public policies designed to expand the stock of rental housing, result in renewed growth in homeless shelter use in that city.

The causal links that provide our explanation for the pattern of change in Calgary are broken at two points in Edmonton. The key for understanding the lack of variability in shelter use in Edmonton is the fact that the housing market in that city has been much better able to maintain the stock of rental housing units. Explaining the reason for the different response in the supply of rental accommodations in Calgary versus Edmonton remains a puzzle at this point. It is an important issue deserving deeper analysis than we can give here. We suggest that gaining an understanding of this difference should be a research priority. ${ }^{11}$

It is noteworthy that our conclusion - that the ability of a local housing market to maintain its stock of rental accommodations is an important determinant of the demand for shelter space is consistent with analyses elsewhere. Recent studies examining homelessness in the US, for example, report that the incidence of homelessness has more to do with conditions in housing markets than it does with social pathologies, drug usage or deficiencies in mental health treatments. ${ }^{12}$ Those studies conclude that even modest changes in housing markets have substantial effects on the incidence of homelessness and that public policies aimed at maintaining the stock of affordable rental accommodations are key to reducing the incidence of homelessness and, by extension, the demand for shelter space.

All of this suggests that recent efforts of the Alberta Ministry of Housing and Urban Affairs to increase the stock of affordable housing - by funding new construction and by using rent subsidy programs as a way of keeping rental units available to the market - is an appropriate public policy response. Our research suggests that it is a particularly appropriate response for attacking the problem of homelessness in Calgary, where the local housing market has proven less able than the housing market in Edmonton to maintain the stock of rental accommodations. We recommend a research agenda aimed at understanding this difference in housing markets in the two cities. Finally, because we believe that maintaining the stock of rental accommodations can generate a large payoff in terms of reducing homelessness and so the demand for homeless shelter spaces, we suggest that the government investigate the potential benefits of engaging the energy and efficiency of the private sector to increase the supply of affordable housing through the provision of tax and regulatory incentives. ${ }^{13}$

11 One possibility is that the Calgary housing market is geared more toward higher-end housing than is Edmonton. If the price of high-end housing is rising faster than rents in units most attractive to those most at risk of homelessness, then the private sector will naturally increase the supply of the former more than the latter. A contributing factor here might be found in the economic characteristics of in-migrants to Calgary as opposed to elsewhere. Another possibility is that over our period of analysis, more land appropriate for development of rental accommodations may have been made available in Edmonton than in Calgary. These are important questions for further research as we feel that differences in housing markets are at the heart of explanations for different patterns of shelter use in Calgary and Edmonton.

12 See, for example, John Quigley and Steven Raphael, The Economics of Homelessness: The Evidence from North America, European Journal of Housing Policy, Volume 1, No. 3, pp. 323-336, 2001 and John Quigley, Steven Raphael and Eugene Smolensky Homeless in California, Public Policy Institute of California, 2001.

13 For specific policy proposals along these lines see Steele and Tomlinson, Increasing the Affordability of Rental Housing in Canada: An Assessment of Supply-Side Measures, The School of Public Policy, University of Calgary, SPP Research Papers, Vol. 3, Issue 2, September 2010. 



\section{ABOUT THIS PUBLICATION}

The School of Public Policy Research Papers provide in-depth, evidence-based assessments and recommendations on a range of public policy issues. Research Papers are put through a stringent peer review process prior to being made available to academics, policy makers, the media and the public at large. Views expressed in The School of Public Policy Research Papers are the opinions of the author(s) and do not necessarily represent the view of The School of Public Policy.

\section{OUR MANDATE}

The University of Calgary is home to scholars in 16 faculties (offering more than 80 academic programs) and 36 Research Institutes and Centres including The School of Public Policy. Under the direction of Jack Mintz, Palmer Chair in Public Policy, and supported by more than 100 academics and researchers, the work of The School of Public Policy and its students contributes to a more meaningful and informed public debate on fiscal, social, energy, environmental and international issues to improve Canada's and Alberta's economic and social performance.

The School of Public Policy achieves its objectives through fostering ongoing partnerships with federal, provincial, state and municipal governments, industry associations, NGOs, and leading academic institutions internationally. Foreign Investment Advisory Committee of the World Bank, International Monetary Fund, Finance Canada, Department of Foreign Affairs and International Trade Canada, and Government of Alberta, are just some of the partners already engaged with the School's activities.

For those in government, The School of Public Policy helps to build capacity and assists in the training of public servants through degree and non-degree programs that are critical for an effective public service in Canada. For those outside of the public sector, its programs enhance the effectiveness of public policy, providing a better understanding of the objectives and limitations faced by governments in the application of legislation.

\section{DISTRIBUTION}

Our publications are available online at www.policyschool.ca.

\section{DISCLAIMER}

The opinions expressed in these publications are the authors' alone and therefore do not necessarily reflect the opinions of the supporters, staff, or boards of The School of Public Policy.

\section{COPYRIGHT}

Copyright (C) 2011 by The School of Public Policy.

All rights reserved. No part of this publication may be reproduced in any manner whatsoever without written permission except in the case of brief passages quoted in critical articles and reviews.

\section{ISSN}

1919-112x SPP Research Papers (Print)

1919-1138 SPP Research Papers (Online)

\section{DATE OF ISSUE}

September 2011

\section{MEDIA INQUIRIES AND INFORMATION}

For media inquiries, please contact Morten Paulsen at 403-453-0062.

Our web site, www.policyschool.ca, contains more information about The School's events, publications, and staff.

\section{DEVELOPMENT}

For information about contributing to The School of Public Policy, please contact Candice Naylen by telephone at 403-210-7099 or by e-mail at cnaylen@ucalgary.ca.

\section{EDITOR}

Timothy Giannuzzi 


\section{RECENT PUBLICATIONS BY THE SCHOOL OF PUBLIC POLICY}

INCOME SUPPORT FOR PERSONS WITH DISABILITIES

http:// policyschool.ucalgary.ca/files/publicpolicy/Kneebone_Disability_Study.pdf

Ronald Kneebone and Oksana Grynishak | September 2011

PLUCKING THE GOLDEN GOOSE: HIGHER ROYALTY RATES ON THE OIL SANDS GENERATE SIGNIFICANT INCREASES IN GOVERNMENT REVENUE

http:/ / policyschool.ucalgary.ca/files/publicpolicy/KMckenzie\%20comm\%20sept11.pdf

Kenneth J. McKenzie | September 2011

INVESTMENT REVIEW IN CANADA - WE CAN DO BETTER

http:/ / policyschool.ucalgary.ca/files/ publicpolicy/Herman\%20Invest\%20Canada\%20online.pdf

Lawrence L. Herman | September 201

ENVIRONMENTAL BENEFITS OF USING WIND GENERATION TO POWER PLUG-IN HYBRID ELECTRIC VEHICLES

http:// policyschool.ucalgary.ca/files/ publicpolicy/enviro\%20hybrid\%20wind\%20energy.pdf

Mahdi Hajian, Monishaa Manickavasagam, William D. Rosehart and Hamidreza Zareipour | August 2011

A FRESH START ON IMPROVING ECONOMIC COMPETITIVENESS AND PERIMETER SECURITY

http:/ / policyschool.ucalgary.ca/files/ publicpolicy/dburney.pdf

Derek H. Burney | August 2011

PIIGS “g” US?

http:/ / policyschool.ucalgary.ca/files/ publicpolicy/US\%20debt\%20crisis.pdf

Stephen R. Richardson | July 2011

RHETORIC AND REALITIES: WHAT INDEPENDENCE OF THE BAR REQUIRES OF LAWYER REGULATION

http:// policyschool.ucalgary.ca/files/publicpolicy/A_Woolley_lawregulat_c.pdf

Alice Woolley | June 2011

TAX IMPACT OF BC'S HST DEBATE ON INVESTMENT AND COMPETITIVENESS

http:/ / policyschool.ucalgary.ca/ files/ public policy/tax\%20impact\%20BCHST\%20communique\%20c.pdf Jack Mintz | May 2011

SMALL BUSINESS TAXATION: REVAMPING INCENTIVES TO ENCOURAGE GROWTH

http:/ / policyschool.ucalgary.ca/files/publicpolicy/mintzchen\%20small\%20business\%20tax\%20c.pdf Duanjie Chen \& Jack Mintz | May 2011

IS THIS THE END OF THE TORY DYNASTY? THE WILDROSE ALLIANCE IN ALBERTA POLITICS http:// policyschool.ucalgary.ca/files/publicpolicy/wildrose\%20online\%20final3.pdf

Anthony M. Sayers \& David K. Stewart | May 2011

CANADA'S WORLD CAN GET A LOT BIGGER: THE GROUP OF 20, GLOBAL GOVERNANCE AND SECURITY http:/ / policyschool.ucalgary.ca/files/ publicpolicy/G20\%20Heinbecker.pdf

Paul Heinbecker | May 2011

CAN THE G-20 SAVE THE ENVIRONMENT? POTENTIAL IMPACT OF THE G-20 ON INTERNATIONAL ENVIRONMENT POLICY

http:/ / policyschool.ucalgary.ca/files/ publicpolicy/G20\%20.pdf

Barry Carin | April 2011

THE IMPACT OF SALES TAX REFORM ON ONTARIO CONSUMERS:

A FIRST LOOK AT THE EVIDENCE

http:/ / policyschool.ucalgary.ca/files/ publicpolicy/ontario\%20sales\%20tax\%20reform4.pdf

Michael Smart | March 2011 